\title{
ANALISIS PENGARUH PROMOSI DAN KARAKTERISTIK KONSUMEN TERHADAP KEPUTUSAN PEMBELIAN TEH CELUP WALINI DI KOTA BANDUNG
}

\section{(Analysis of The Influence of Promotion and Consumer Characteristics on Purchasing Decision of Walini Tea Bag in Bandung City)}

\author{
L. Farnesia, W. Roessali dan S.I. Santoso \\ Jurusan Pertanian Fakultas Peternakan dan Pertanian Universitas Diponegoro \\ Email:lasanafarnesia@yahoo.com \\ Diterima 15 Maret 2017, disetujui 28 Maret 2017
}

\begin{abstract}
ABSTRAK
Tujuan dari penelitian ini adalah untuk mengetahui pengaruh bauran promosi terhadap keputusan pembelian konsumen. Penelitian ini menggunakan 100 responden dengan metode accidental sampling. Analisis data menggunakan analisis deskriptif, analisis faktor dan regresi linier berganda. Hasil penelitian menunjukkan bahwa periklanan, penjualan pribadi, promosi penjualan, pemasaran langsung, hubungan masyarakat, jenis kelamin, usia, pekerjaan dan pendidikan mempunyai pengaruh yang signifikan terhadap keputusan pembelian secara serempak. Periklanan, promosi penjualan, pemasaran langsung, jenis kelamin, usia dan pekerjaan mempunyai pengaruh yang sangat signifikan secara parsial, sedangkan penjualan pribadi, hubungan masyarakat dan pendidikan tidak signifikan.
\end{abstract}

Kata Kunci: pemasaran, promosi, keputusan pembelian, teh celup walini

\begin{abstract}
The purpose of this research was to find out the influence of promotional mix on consumers purchasing decision. This study took 100 respondents and used accidental sampling method. The data analysis technique used descriptive analysis, factor analysis and multiple linear regression analysis. The result of this research showed that advertising, personal selling, sales promotion, direct marketing, public relations, gender, age, occupation and education had a significant influence on purchasing decision simultaneously. Advertising, sales promotion, direct marketing, gender, age and occupation of consumers had a highly significant influence on purchasing decision while personal selling, public relations and education had no significant influence.
\end{abstract}

Keywords: marketing, promotion, purchasing decision, walini tea bag.

\section{PENDAHULUAN}

Pendirian suatu perusahaan pada umumnya dilatar belakangi oleh adanya tujuan tertentu yang ingin dicapai seperti memperoleh keuntungan sebesar-besarnya melalui penjualan barang atau jasa yang dihasilkan. Perusahaan yang ingin mempertahankan dan meningkatkan penjualannya tersebut membutuhkan suatu strategi usaha 
seperti strategi pemasaran. Menurut Rachmawati (2011) strategi pemasaran penting untuk dirancang karena merupakan sebuah rencana yang memungkinkan perusahaan mengoptimalkan penggunaan sumber dayanya untuk mencapai tujuan pemasaran dan perusahaan. Strategi pemasaran dapat dilakukan dengan menerapkan bauran pemasaran yang tepat, khususnya pada aspek promosi karena melalui kegiatan promosi perusahaan diharapkan mampu menarik perhatian konsumen sehingga akan berpengaruh terhadap keputusan pembelian.

PT. Perkebunan Nusantara (PTPN) VIII adalah perkebunan milik negara yang kegiatan usahanya meliputi pembudidayaan tanaman, pengolahan/produksi dan penjualan komoditi hasil perkebunan khususnya teh. Perusahaan ini memiliki unit usaha yang dibentuk guna mengembangkan produk hulu teh menjadi produk hilir teh yang dikenal dengan nama Industri Hilir Teh (IHT). Teh yang diproduksi oleh IHT PTPN VIII terdiri dari tiga merek yang berbeda, satu diantaranya adalah Walini. Teh Walini diproduksi dalam kemasan berupa teh celup, teh seduh dan teh instan, tetapi produk yang menjadi unggulan Walini adalah teh celup.

Salah satu strategi yang diterapkan oleh IHT PTPN VIII dalam menunjang kegiatan pemasarannya adalah dengan melakukan kegiatan promosi. Menurut Tjiptono (2007) promosi adalah suatu bentuk komunikasi pemasaran berupa aktivitas untuk menyebarkan informasi, mempengaruhi atau membujuk serta meningkatkan pasar sasaran atas perusahaan dan produknya agar bersedia menerima, membeli serta loyal pada produk yang ditawarkan perusahaan yang bersang-kutan. Pencapaian tujuan IHT PTPN VIII serta kemampuan untuk bersaing dan berkembang dalam persaingan usaha dapat dilakukan dengan memberikan perhatian lebih pada kegiatan promosi tersebut. Menurut Hermawan (2012) kegiatan promosi merupakan salah satu komponen yang menjadi prioritas dari kegiatan pemasaran. Pemilihan kegiatan promosi yang tepat dapat berdampak positif pada hasil penjualan produk karena menurut
Swasta dan Irawan (2001) promosi merupakan salah satu faktor penentu keberhasilan program pemasaran.

Bauran promosi terdiri dari periklanan, penjualan pribadi, promosi penjualan, pemasaran langsung dan hubungan masyarakat (kehumasan). Periklanan adalah bentuk presentasi berupa gagasan, barang atau jasa oleh sponsor yang telah ditentukan. Penjualan pribadi merupakan interaksi tatap muka dengan satu atau beberapa calon pembeli dengan maksud untuk melakukan presentasi, menjawab pertanyaan dan memperoleh pemesanan. Pemasaran langsung adalah sistem pemasaran interaktif yang menggunakan satu atau lebih media untuk mempengaruhi satu tanggapan atau transaksi tanpa menggunakan perantara pemasaran. Kehumasan merupakan berbagai program yang dirancang untuk mempromosikan atau melindungi citra perusahaan atau masing-masing produknya (Kotler dan Keller, 2008).

Keputusan pembelian merupakan suatu keputusan atau tindakan dari dua atau lebih pilihan alternatif seorang konsumen yang hendak melakukan pilihan dan memilih salah satu diantaranya (Sumarwan, 2011). Pengambilan keputusan pada konsumen dapat dipengaruhi oleh berbagai faktor yang bersifat individual (internal) maupun yang berasal dari lingkungan eksternal (Simamora, 2000). Faktor internal tersebut berasal dari setiap konsumen itu sendiri seperti faktor pribadi berupa usia, pekerjaan, gaya hidup dan kepribadian. Indikator keputusan pembelian terdiri dari kemantapan pada sebuah produk, kebiasaan dalam membeli produk, memberikan rekomendasi kepada orang lain dan melakukan pembelian ulang (Kotler, 2007).

Penelitian ini bertujuan untuk (1) mengetahui strategi pemasaran yang dilakukan Industri Hilir Teh PT Perkebunan Nusantara VIII, khususnya pada kegiatan promosi; (2) menganalisis respon konsumen terhadap promosi yang dilakukan oleh Industri Hilir Teh PT Perkebunan Nusantara VIII dan (3) menganalisis faktor-faktor yang mempengaruhi keputusan pembelian produk Teh Celup Walini. 


\section{METODE PENELITIAN}

Penelitian dilaksanakan pada bulan November sampai bulan Desember 2016 di 5 pasar swalayan yang berada di Kota Bandung bagian timur. Kota Bandung bagian timur ditentukan sebagai lokasi penelitian karena di daerah tersebut terdapat pasar-pasar swalayan yang menjual produk Teh Celup Walini dan merupakan daerah asal produksi Teh Celup Walini.

Penentuan sampel dilakukan dengan teknik non probability sampling menggunakan metode accidental sampling. Jumlah sampel ditentukan dengan persyaratan yang ditentukan oleh Hair et al. (2006) yang menyatakan bahwa batas minimum jumlah sampel adalah 5 kali dari jumlah parameter yang diobservasi dan data yang diolah dengan regresi linier berganda disarankan menggunakan sampel sejumlah 100 responden, sehingga besarnya sampel dalam penelitian ini adalah 100 responden. Responden dalam penelitian ini adalah konsumen Teh Celup Walini, baik yang berperan sebagai pemakai, pembeli maupun pengambil keputusan pembelian produk.

Instrumen utama yang digunakan dalam penelitian ini adalah kuesioner (daftar pertanyaan). Pengukuran instrumen penelitian menggunakan skala Likert, nominal, ordinal dan rasio seperti yang tertera pada Tabel 1 .

Pengukuran dengan skala Likert pada penelitian ini menggunakan skor angka 1 yang bermakna sangat tidak setuju sampai dengan angka 5 yang bermakna sangat setuju. Jumlah skor berdasarkan skala Likert dari seluruh responden kemudian dikategorikan seperti yang tertera pada Tabel 2 .

Jumlah skor tersebut menggambarkan respon konsumen terhadap promosi dengan kriteria:

1. Jika Kuartil III $<$ Skor $<$ Maksimal, artinya respon konsumen dinilai sangat baik.

Tabel 1. Operasional Variabel

\begin{tabular}{|c|c|c|}
\hline Variabel & Indikator & Skala Pengukuran \\
\hline \multirow[t]{3}{*}{$\overline{\text { Advertising (X1) }}$} & 1. Media cetak & \multirow[t]{3}{*}{ Likert } \\
\hline & 2. Reklame & \\
\hline & 3. Branding kendaraan & \\
\hline \multirow[t]{3}{*}{ Personal Selling (X2) } & 1. Salesman & \multirow[t]{3}{*}{ Likert } \\
\hline & 2. Sampel produk & \\
\hline & 3. Pameran dagang & \\
\hline \multirow[t]{3}{*}{ Sales Promotion (X3) } & 1. Pemberian hadiah & \multirow[t]{3}{*}{ Likert } \\
\hline & 2. Potongan harga atau diskon & \\
\hline & 3. Pemberian bonus & \\
\hline \multirow[t]{3}{*}{ Direct Marketing (X4) } & 1. Media sosial & \multirow[t]{3}{*}{ Likert } \\
\hline & 2. Stand atau kios & \\
\hline & 3. Situs web & \\
\hline \multirow[t]{3}{*}{ Public Relations (X5) } & 1. Acara khusus & \multirow[t]{3}{*}{ Likert } \\
\hline & 2. Sponsorship & \\
\hline & 3. Pelayanan masyarakat & \\
\hline Jenis Kelamin (Z1) & Pria dan wanita & Nominal \\
\hline Usia $(Z 2)$ & Usia & Rasio \\
\hline Pendidikan (Z3) & Lulus SMA, Diploma, Sarjana, Magister, Doktor & Ordinal \\
\hline Pekerjaan (Z4) & $\begin{array}{l}\text { Tidak bekerja, pelajar, PNS, TNI/POLRI, pegawai } \\
\text { swasta, wirausaha, lainnya }\end{array}$ & Nominal \\
\hline \multirow{4}{*}{$\begin{array}{l}\text { Keputusan Pembelian } \\
\text { (Y) }\end{array}$} & 1. Kemantapan pada sebuah produk & \multirow[t]{4}{*}{ Likert } \\
\hline & 2. Kebiasaan dalam membeli produk & \\
\hline & 3. Memberikan rekomendasi kepada orang lain & \\
\hline & 4. Melakukan pembelian ulang & \\
\hline
\end{tabular}


Tabel 2. Jumlah Skor Responden

\begin{tabular}{cc}
\hline \hline Keterangan & Jumlah Skor \\
\hline Maksimal & 100 responden $\times 5=500$ \\
Kuartil III & 100 responden $\times 4=400$ \\
Median & 100 responden $\times 3=300$ \\
Kuartil I & 100 responden $\times 2=200$ \\
Minimal & 100 responden $\times 1=100$ \\
\hline
\end{tabular}

Sumber: Sugiyono, 2008.

2. Jika Median $<$ Skor $<$ Kuartil III, artinya respon konsumen dinilai baik.

3. Jika Kuartil I < Skor $<$ Median, artinya respon konsumen dinilai kurang baik.

4. Jika Minimal < Skor $<$ Kuartil I, artinya respon konsumen dinilai tidak baik.

Analisis faktor diinterpretasikan dengan Communalities. Communalities pada dasarnya adalah jumlah varians dari suatu variabel mula-mula yang bisa dijelaskan oleh faktor yang ada (Santoso, 2006). Analisis untuk mengetahui faktor-faktor yang mempengaruhi keputusan pembelian Teh Celup Walini menggunakan analisis regresi linier berganda. Data yang akan dianalisis terlebih dahulu melalui serangkaian pengujian untuk memenuhi syarat asumsi klasik yang terdiri dari uji normalitas, uji autokorelasi, uji multikolinearitas dan uji heteroskedastisitas. Pengujian hipotesis dalam penelitian ini menggunakan uji $\mathrm{F}$ (uji serempak) dan uji $\mathrm{t}$ (uji parsial) serta dilengkapi dengan analisis koefisien determinasi untuk mengetahui kecocokan model yang digunakan. Persamaan regresi yang digunakan dalam penelitian ini mengacu pada Sugiyono (2008) sehingga dapat dirumuskan sebagai berikut:

$\mathrm{Y}=\mathrm{a}+\mathrm{b}_{1} \cdot \mathrm{X}_{1}+\mathrm{b}_{2} \cdot \mathrm{X}_{2}+\mathrm{b}_{3} \cdot \mathrm{X}_{3}+\mathrm{b}_{4} \cdot \mathrm{X}_{4}+$ $b_{5} \cdot X_{5}+b_{1} \cdot z_{1}+b_{2} \cdot z_{2}+b_{3} \cdot z_{3}+b_{4} \cdot z_{4}+e$

Keterangan:

$\mathrm{Y}=$ Keputusan Pembelian (skor)

$\mathrm{b}=$ Koefisien regresi dari variabel bebas

$\mathrm{a}=$ Konstanta

$\mathrm{X}_{1}=$ Advertising (skor)

$\mathrm{X}_{2}=$ Personal Selling (skor)

$\mathrm{X}_{3}=$ Sales Promotion (skor)

$\mathrm{X}_{4}=$ Direct Marketing (skor)

$\mathrm{X}_{5}=$ Public Relations (skor)
$\mathrm{Z}_{1}=\operatorname{Jenis} \operatorname{Kelamin}(0=$ pria, $1=$ wanita $)$

$Z_{2}=$ Usia (tahun)

$\mathrm{Z}_{3}=$ Pendidikan $(1=$ Lulus SMA, 2 = Diploma, $3=$ Sarjana, $4=$ Magister, $5=$ Doktor)

$\mathrm{Z}_{4}=$ Pekerjaan $(0=$ Tidak bekerja dan pelajar, 1 = PNS, TNI/POLRI, pegawai swasta, wirausaha dan lainnya)

e $=$ Standar error

\section{HASIL DAN PEMBAHASAN}

Berdasarkan penelitian yang telah dilakukan, dapat diperoleh hasil mengenai karakteristik demografi konsumen. Karakteristik konsumen pada penelitian ini dikelompokkan berdasarkan jenis kelamin, usia, pendidikan dan pekerjaan seperti yang tertera pada Tabel 3. Data pada Tabel 3 menunjukkan bahwa konsumen Teh Celup Walini yang menjadi responden didominasi oleh perempuan dengan usia terbanyak pada kelompok usia $21-30$ tahun. Seluruh konsumen Teh Celup Walini tersebut merupakan orang-orang berpendidikan yang didominasi oleh konsumen dengan pendidikan akhir sebagai sarjana serta sebagian besar terdiri dari konsumen yang bekerja sebagai Pegawai Negeri Sipil dan pelajar. Menurut Setiabudi et al. (2013) konsumen yang berpendidikan cukup baik diasumsikan dapat mengetahui dan memiliki informasi serta pengetahuan luas tentang pentingnya mengkonsumsi produk yang berkualitas dan manfaatnya sebagai salah satu kebutuhan yang memiliki tingkat atau kandungan gizi tinggi yang baik untuk kesehatan.

Berdasarkan hasil penelitian dapat diketahui bahwa Industri Hilir Teh PT Perkebunan Nusantara VIII telah menerapkan strategi pemasaran berupa promosi. Jenis dan bentuk kegiatan promosi yang dilakukan oleh IHT PTPN VIII serta respon konsumen terhadap kegiatan promosinya dapat dilihat pada Tabel 4 .

Tabel 4 menunjukkan bahwa penerapan strategi pemasaran berupa promosi yang dilakukan oleh Industri Hilir Teh PT Perkebunan Nusantara VIII terdiri dari 
Tabel 3. Karakteristik Demografi Konsumen

\begin{tabular}{llcc}
\hline \multicolumn{1}{c}{ Karakteristik } & \multicolumn{1}{c}{ Klasifikasi } & Jumlah & Persentase \\
\hline \multirow{3}{*}{ Jenis Kelamin } & Pria & --- jiwa--- & $---\%{ }^{---}$ \\
& Wanita & 33 & 33 \\
Usia & & 67 & 67 \\
& $\leq 20$ tahun & 5 & 5 \\
& $21-30$ tahun & 36 & 36 \\
& $31-40$ tahun & 17 & 17 \\
& $41-50$ tahun & 17 & 17 \\
Pendidikan & 22 & 22 \\
& 51 -60 tahun & 3 & 3 \\
& Lulus SMA & 22 & 22 \\
& Diploma & 6 & 6 \\
& Sarjana & 43 & 43 \\
Pekerjaan & Magister & 23 & 23 \\
& Doktor & 6 & 6 \\
& Tidak bekerja & 17 & 17 \\
& Pelajar & 20 & 20 \\
& PNS & 20 & 20 \\
& TNI/POLRI & 5 & 5 \\
& Pegawai Swasta & 15 & 15 \\
& Wirausaha & 9 & 9 \\
& Lainnya & 14 & 14 \\
\hline
\end{tabular}

Sumber: Data Primer Diolah, 2016

Tabel 4. Promosi dan Respon Konsumen

\begin{tabular}{|c|c|c|c|c|c|c|c|}
\hline \multirow{2}{*}{ Jenis Promosi } & \multirow{2}{*}{ Bentuk Kegiatan Promosi } & \multicolumn{5}{|c|}{ Skor } & \multirow[b]{2}{*}{ Jumlah } \\
\hline & & 1 & 2 & 3 & 4 & 5 & \\
\hline \multirow{3}{*}{$\begin{array}{l}\text { Advertising } \\
\text { (Periklanan) }\end{array}$} & Iklan pada media cetak & 1 & 11 & 43 & 41 & 4 & 336 \\
\hline & 2. Iklan pada media reklame & 1 & 13 & 47 & 35 & 4 & 328 \\
\hline & $\begin{array}{l}\text { 3. Branding pada kendaraan } \\
\text { operasional perusahaan }\end{array}$ & 1 & 15 & 47 & 33 & 4 & 324 \\
\hline \multirow{3}{*}{$\begin{array}{l}\text { Personal } \\
\text { Selling } \\
\text { (Penjualan } \\
\text { Pribadi) }\end{array}$} & 1. Presentasi oleh salesman & 8 & 18 & 34 & 38 & 2 & 308 \\
\hline & Pemberian sampel produk & 0 & 11 & 26 & 57 & 6 & 358 \\
\hline & Pameran dagang & 0 & 11 & 20 & 58 & 11 & 369 \\
\hline \multirow{2}{*}{$\begin{array}{l}\text { Sales Promotion } \\
\text { (Promosi }\end{array}$} & Pemberian hadiah & 0 & 0 & 37 & 56 & 7 & 370 \\
\hline & Potongan harga atau diskon & 0 & 0 & 31 & 49 & 20 & 389 \\
\hline \multirow{2}{*}{$\begin{array}{l}\text { Penjualan) } \\
\text { Direct }\end{array}$} & Pemberian bonus & 0 & 0 & 32 & 56 & 12 & 381 \\
\hline & $\begin{array}{l}\text { 1. Penggunaan media sosial } \\
\text { (Facebook dan Twitter) }\end{array}$ & 5 & 30 & 45 & 19 & 1 & 281 \\
\hline \multirow{5}{*}{$\begin{array}{l}\text { (Pemasaran } \\
\text { Langsung) } \\
\text { Public Relations } \\
\text { (Hubungan } \\
\text { Masyarakat) }\end{array}$} & 2. Pengadaan stand atau kios & 5 & 24 & 47 & 22 & 2 & 292 \\
\hline & Penggunaan situs web & 5 & 30 & 45 & 19 & 1 & 281 \\
\hline & Acara khusus (senam pagi) & 0 & 12 & 26 & 58 & 4 & 354 \\
\hline & Sponsorship & 0 & 19 & 35 & 41 & 5 & 332 \\
\hline & $\begin{array}{l}\text { 3. Pelayanan masyarakat (grebek } \\
\text { pasar) }\end{array}$ & 0 & 12 & 25 & 59 & 4 & 355 \\
\hline
\end{tabular}

Sumber: Data Primer Diolah, 2016. 
advertising, personal selling, sales promotion, direct marketing dan public relations. Data pada Tabel 4 juga menunjukkan bahwa empat dari lima jenis promosi yang dilakukan yaitu advertising, personal selling, sales promotion dan public relations mendapat respon baik dari konsumen.

Berdasarkan analisis data dengan analisis faktor, dapat diperoleh hasil indikatorindikator yang paling mempengaruhi masingmasing variabel promosi. Hasil analisis faktor tertera pada Tabel 5. Hasil Communalities yang tertera pada Tabel 5 menunjukkan besar pengaruh setiap indikator (bentuk promosi) terhadap variabel-variabel promosi. Berdasarkan hasil tersebut maka dapat disimpulkan bahwa bentuk promosi yang memberikan pengaruh paling besar pada advertising adalah iklan dengan menggunaan reklame dan promosi yang memberikan pengaruh paling besar pada personal selling adalah pameran dagang. Bentuk promosi yang memberikan pengaruh paling besar pada sales promotion adalah pemberian bonus, promosi yang memberikan pengaruh paling besar pada direct marketing adalah penggunaan media sosial dan situs web, sedangkan promosi yang memberikan pengaruh paling besar pada public relations adalah pelayanan masyarakat.
Hasil uji normalitas dengan menggunakan model Kolmogorov-Smirnov mempunyai nilai signifikansi hitung lebih besar dari $5 \%$ atau 0,05 , yaitu 0,711 maka dapat disimpulkan bahwa data berdistibusi normal. Hasil uji autokorelasi dengan menggunakan model Durbin-Watson mempunyai nilai Durbin-Watson yaitu 2,066, maka dapat disimpulkan bahwa tidak terdapat autokorelasi pada data. Hasil uji multikolinearitas dengan menggunakan model Variance Inflation Factor (VIF) mempunyai nilai VIF yang seluruhnya lebih kecil dari 10 , maka dapat disimpulkan bahwa tidak terdapat multikolinearitas antar variabel bebas. Hasil uji heteroskedastisitas dengan menggunakan model Rank Spearman mempunyai nilai signifikansi lebih dari 0,05 maka dapat disimpulkan bahwa tidak terdapat hubungan heteroskedastisitas.

Hasil uji asumsi klasik melalui uji normalitas, autokorelasi, multikolinearitas dan heteroskedastisitas yang sudah dilakukan menunjukkan hasil yang sesuai dengan persyaratan untuk analisis regresi. Berdasarkan hasil tersebut maka dapat diketahui bahwa asumsi klasik yang disyaratkan untuk analisis regresi sudah terpenuhi. Berdasarkan analisis data dengan analisis regresi linier berganda dan pengujian hipotesis dengan menggunakan

Tabel 5. Hasil Analisis Faktor

\begin{tabular}{llc}
\hline \multicolumn{1}{c}{ Variabel } & \multicolumn{1}{c}{ Indikator } & Extraction \\
\hline Advertising & Media cetak & 0,932 \\
& Reklame & 0,975 \\
Personal Selling & Branding kendaraan & 0,941 \\
& Salesman & 0,385 \\
& Sampel produk & 0,806 \\
Sales Promotion & Pameran dagang & 0,894 \\
& Hadiah & 0,812 \\
& Diskon & 0,899 \\
Direct Marketing & Bonus & 0,931 \\
& Media sosial & 0,983 \\
& Stand/Kios & 0,921 \\
Public Relations & Situs web & 0,983 \\
& Acara khusus & 0,955 \\
& Sponsorship & 0,850 \\
& Pelayanan masyarakat & 0,960 \\
\hline
\end{tabular}


uji $F$ (serempak) dan uji t (parsial) seperti yang tertera pada Tabel 6 .

Berdasarkan data pada Tabel 6, dapat diperoleh persamaan regresi sebagai berikut: $\mathrm{Y}=5,170+0,317 \mathrm{X} 1-0,148 \mathrm{X} 2+0,339 \mathrm{X} 3$ $+0,173 X 4+0,081 X 5+0,806 Z 1+0,030$ $\mathrm{Z} 2-0,015 \mathrm{Z} 3+0,647 \mathrm{Z} 4+\mathrm{e}$

Nilai koefisien determinasi dari data yang sudah dianalisis adalah 0,528 . Koefisien determinasi sebesar 0,528 mempunyai arti bahwa promosi yang terdiri dari variabel advertising, personal selling, sales promotion, direct marketing dan public relations serta karakteristik konsumen berupa jenis kelamin, usia, pekerjaandan pendidikan dapat menjelaskan variabel keputusan pembelian sebesar 52,8\% dan sisanya dipengaruhi atau dijelaskan oleh variabel lain yang tidak dimasukan dalam model.

Hasil analisis data dengan uji $F$ menunjukkan bahwa promosi berupa advertising, personal selling, sales promotion, direct marketing, public relations serta karakteristik konsumen yang terdiri dari jenis kelamin, usia, pekerjaan dan pendidikan secara bersama-sama memberikan pengaruh nyata terhadap keputusan pembelian.

Hasil uji $t$ menunjukkan bahwa advertising memberikan pengaruh positif terhadap keputusan pembelian, artinya semakin tinggi nilai advertising maka keputusan pembelian konsumen akan meningkat. Berdasarkan hasil tersebut dapat disimpulkan bahwa advertising berupa pemasangan iklan pada media cetak, reklame dan branding pada kendaraan operasional perusahaan dapat mempengaruhi tindakan konsumen dalam melakukan keputusan pembelian pada produk Teh Celup Walini. Hasil penelitian ini sesuai dengan penelitian yang dilakukan oleh Foret dan Prochazka (2006) yang menunjukkan hasil bahwa advertising pada produk minuman kopi merupakan faktor paling penting yang menjadi alasan konsumen untuk melakukan keputusan pembelian. Hasil tersebut juga didukung dan sesuai dengan penelitian Hidayat dan Istiyanto (2012) yang menunjukkan hasil bahwa periklanan mempunyai pengaruh yang positif dan signifikan terhadap keputusan pembelian produk jamu. Hal ini sesuai dengan pendapat Hermawan (2012) yang menyatakan bahwa melalui periklanan para konsumen potensial dibuat untuk memerhatikan dan peduli terhadap produk yang memberikan manfaat bagi mereka sehingga memberikan alasan bagi mereka untuk membeli.

Sales promotion memberikan pengaruh positif terhadap keputusan pembelian, artinya semakin tinggi nilai sales promotion maka keputusan pembelian konsumen akan meningkat. Berdasarkan hasil tersebut dapat

Tabel 6. Hasil Analisis Regresi Linier Berganda

\begin{tabular}{lccc}
\hline \multicolumn{1}{c}{ Variabel } & Koefisien Regresi & $\mathrm{t}$ & \multicolumn{1}{c}{ Sig. } \\
\hline Konstanta (a) & 5,170 & 4,802 & 0,000 \\
Advertising (X1) & 0,317 & 5,112 & $0,000^{* *}$ \\
Personal Selling (X2) & $-0,148$ & $-1,260$ & 0,211 \\
Sales Promotion (X3) & 0,339 & 2,911 & $0,005^{* *}$ \\
Direct Marketing (X4) & 0,173 & 2,796 & $0,006^{* *}$ \\
Public Relations (X5) & 0,081 & 1,229 & 0,222 \\
Jenis Kelamin (Z1) & 0,806 & 2,794 & $0,006^{* *}$ \\
Usia (Z2) & 0,030 & 2,624 & $0,010^{* *}$ \\
Pendidikan (Z3) & $-0,015$ & $-0,113$ & 0,910 \\
Pekerjaan (Z4) & 0,647 & 2,064 & $0,042^{*}$ \\
\hline \hline F & & 13,290 & 0,000 \\
Adjusted R Square & & 0,528 & - \\
\hline
\end{tabular}

Sumber: Data Primer Diolah, 2016.

Keterangan: $\quad *$ Nyata pada tingkat kepercayaan $95 \%(\alpha=0,05)$.

**Nyata pada tingkat kepercayaan $99 \%(\alpha=0,01)$. 
disimpulkan bahwa sales promotion berupa promo dengan pemberian hadiah, potongan harga atau diskon dan pemberian bonus dapat mempengaruhi tindakan konsumen dalam melakukan keputusan pembelian pada produk Teh Celup Walini. Hasil penelitian ini sesuai dengan penelitian Prasetyo dan Wahyuati (2016) yang menunjukkan hasil bahwa pengaruh sales promotion terhadap keputusan pembelian pada produk Kopiganes adalah signifikan dengan kontribusi sales promotion terhadap keputusan pembelian sebesar 9,06\%. Hal ini sesuai dengan pendapat Kotler dan Keller (2008) yang menyatakan bahwa promosi penjualan merupakan unsur utama dalam kampanye pemasaran yang dirancang untuk merangsang pembelian produk dengan lebih cepat dan lebih besar oleh konsumen (Kotler dan Keller, 2008).

Direct marketing memberikan pengaruh positif terhadap keputusan pembelian, artinya semakin tinggi nilai direct marketing maka keputusan pembelian konsumen akan meningkat. Berdasarkan hasil tersebut dapat disimpulkan bahwa direct marketing berupa promosi di media sosial seperti Facebook dan Twitter, pengadaan stand atau kios dan melalui situs web dapat mempengaruhi tindakan konsumen dalam melakukan keputusan pembelian pada produk Teh Celup Walini. Hasil penelitian ini sesuai dengan penelitian Purnama dan Pralina (2016) yang menunjukkan hasil bahwa terdapat pengaruh yang signifikan antara direct marketingyang terdiri dari face to face selling, telemarketing dan online marketing terhadap keputusan pembelian konsumen. Hal ini sesuai dengan pendapat Kotler dan Keller (2008) yang menyatakan bahwa pemasaran langsung dapat mempengaruhi satu tanggapan atau transaksi terukur pada lokasi manapun melalui saluransaluran langsung kepada konsumen untuk menjangkau dan menyerahkan barang dan jasa kepada pelanggan tanpa menggunakan perantara pemasaran.

Jenis kelamin mempunyai pengaruh yang nyata terhadap keputusan pembelian. Konsumen Teh Celup Walini berdasarkan jenis kelamin didominasi oleh konsumen wanita. Kondisi ini menunjukkan bahwa keputusan pembelian banyak dipengaruhi oleh konsumen wanita. Menurut Setiabudi et al. (2013) perempuan pada umunya lebih berperan sebagai pengambil keputusan dalam kegiatan berbelanja atau pembelian kebutuhan rumah tangga. Hasil penelitian ini sesuai dengan penelitian yang dilakukan oleh Kusa et al. (2014) yang menunjukkan hasil bahwa terdapat perbedaan yang signifikan dalam gaya pembelian antara pria dan wanita yang berarti jika jenis kelamin mempunyai peran penting dalam motif pembelian.

Usia mempunyai pengaruh yang nyata terhadap keputusan pembelian. Konsumen Teh Celup Walini berdasarkan kelompok usia mempunyai responden terbanyak pada kelompok usia 21 - 30 tahun yang berarti keputusan pembelian banyak dipengaruhi oleh konsumen pada kelompok usia tersebut. Menurut Setiabudi et al. (2013) kelompok usia dewasa lanjut (25 - 35 tahun) memiliki tingkat kesadaran yang tinggi dan telah memahami kandungan gizi pada suatu produk yang baik bagi kesehatan diri sendiri dan anggota keluarganya. Hasil penelitian ini tidak sesuai dengan penelitian yang dilakukan oleh Devi dan Hartono (2015) yang menunjukkan hasil bahwa tidak adanya pengaruh secara nyata usia terhadap keputusan konsumen dalam membeli sayuran organik.

Pekerjaan mempunyai pengaruh yang nyata terhadap keputusan pembelian. Konsumen Teh Celup Walini berdasarkan pekerjaan mempunyai responden terbanyak pada konsumen yang bekerja sebagai Pegawai Negeri Sipil dan pelajar yang berarti keputusan pembelian banyak dipengaruhi oleh konsumen dengan pekerjaan tersebut. Hasil penelitian ini tidak sesuai dengan penelitian yang dilakukan oleh Rouzbahani et al. (2013) yang menunjukkan hasil bahwa pekerjaan tidak memberikan pengaruh terhadap keputusan pembelian.

\section{SIMPULAN DAN SARAN}

Berdasarkan hasil penelitian dan pembahasan, maka dapat ditarik beberapa kesimpulan sebagai berikut: 
1.Industri Hilir Teh PT Perkebunan Nusantara VIII telah menerapkan strategi pemasaran berupa promosi yang terdiri dari advertising, personal selling, sales promotion, direct marketing dan public relations.

2. Diantara lima jenis promosi yang dilakukan oleh Industri Hilir Teh PT Perkebunan Nusantara VIII, konsumen mempunyai respon yang baik pada empat jenis promosi yaitu advertising, personal selling, sales promotion dan public relations.

3.Keputusan pembelian Teh Celup Walini dipengaruhi oleh faktor eksternal berupa promosi yang terdiri dari advertising, sales promotion dan direct marketing, serta faktor internal yang terdiri dari jenis kelamin, usia dan pekerjaan.

Berdasarkan hasil penelitian, pembahasan dan kesimpulan yang diperoleh, maka saran yang dapat diberikan yaitu:

1. Industri Hilir Teh PTPN VIII disarankan untuk menilai efektivitas promosi perusahaan terhadap kinerja penjualan dan memperbaiki permasalahan yang terdapat pada kegiatan promosi.

2. Peneliti selanjutnya dapat mengembangkan penelitian ini dengan menganalisis faktor lain yang dapat mempengaruhi keputusan pembelian konsumen, sehingga mampu memberikan saran lain kepada perusahaan agar dapat meningkatkan jumlah pembelian produk yang dihasilkan melalui pembelian konsumen.

\section{DAFTAR PUSTAKA}

Devi, S.R.M. dan G. Hartono. 2015. Faktorfaktor yang mempengaruhi keputusan konsumen dalam membeli sayuran organik. J. Ilmu Pertanian. 27 (1): 60-67.

Foret, M. dan P. Prochazka. 2006. Behaviour and decision making of Czech consumers when buying beverages. J. AGRIC ECON. 52 (7): 341-346.

Hair, J.F., W.C. Black, B.J. Babin, R.E. Anderson and R.L. Tatham. 2006. Multivariate Data Analysis. 6 Ed.,
Prentice Hall, New Jersey.

Hermawan, A. 2012. Komunikasi Pemasaran. Erlangga, Jakarta.

Hidayat, M. dan B. Istiyanto. 2012. Pengaruh citra produk dan periklanan terhadap keputusan pembelian jahe wangi $\mathrm{CV}$. Intrafood. J. GRADUASI. 28 (11): 18-35.

Kotler, P. 2007. Manajemen Pemasaran. Edisi 12, Indeks, Jakarta.

Kotler, P. dan K.L. Keller. 2008. Manajemen Pemasaran. Edisi 12, Indeks, Jakarta.

Kusa, A., Z. Danechova, S. Findra and M. Sabo. 2014. Gender differences in purchase decision-making styles. J. Science and Theology. 10 (5): 113-123.

Prasetyo, A. Dan A. Wahyuati. 2016. Pengaruh strategi promosi dan word of mouth terhadap keputusan pembelian pada Kopiganes. J. Ilmu dan Riset Manajemen. 5 (1): 1-17.

Purnama, R. dan A.R. Pralina. 2016. Pengaruh direct marketing terhadap keputusan pembelian di Restoran The Centrum Bandung. J. Tourism and Hospitality Essentials. 6 (1): 973-982.

Rachmawati, R. 2011. Peranan bauran pemasaran (marketing mix) terhadap peningkatan penjualan (sebuah kajian terhadap bisnis restoran). J. Kompetensi Teknik. 2 (2): 143-150.

Rouzbahani, M.T., M. Rezai, A.A. Goudarzi dan S.M. Naghibi. 2013. The effect of individual factors on consumers' purchasing decisions. J. Basic and Applid Scientific Research. 3 (1): 1149-1156.

Santoso, S. 2006. Menggunakan SPSS untuk Statistik Parametrik. PT Elex Media Komputindo, Jakarta.

Setiabudi, M.U., W.B. Parera dan R.A. FarFar. 2013. Proses pengambilan keputusan konsumen dalam pembelian sayuran segar studi kasus Hypermart Ambon City Center Kota Ambon. J. Agribisnis Kepulauan. 1 (4): 25-40.

Simamora, B. 2000. Panduan Riset Perilaku Konsumen. PT Gramedia Pustaka Utama, Jakarta.

Sugiyono. 2008. Metode Penelitian Kuantitatif Kualitatif dan R\&D. Alfabeta, 
Bandung.

Sumarwan, U. 2011. Perilaku Konsumen:

Teori dan Penerapannya dalam

Pemasaran. Ghalia Indonesia, Bogor.

Swasta, B dan Irawan. 2001. Manajemen
Pemasaran Modern. Edisi 2. Liberty Offset. Yogyakarta.

Tjiptono, F. 2007. Manajemen Penjualan

Produk. Cetakan Pertama, Kanisius, Yogyakarta. 